\title{
Anticancer activity of phenoxazines produced by bovine erythrocytes on colon cancer cells
}

\author{
TAKESHI NAKACHI ${ }^{1}$, TAKAFUMI TABUCHI ${ }^{1}$, AKIRA TAKASAKI ${ }^{2}$, \\ SADAO ARAI ${ }^{3}$, KEISUKE MIYAZAWA ${ }^{4}$ and AKIO TOMODA ${ }^{4}$
${ }^{1}$ Fourth Department of Surgery, Tokyo Medical University, Ibaraki Medical Center, 3-20-1 Chuo, Ami, Ibaraki 300-0395;
${ }^{2}$ Department of Geriatrics, Tokyo Medical University, Tokyo 160-0023; Departments of ${ }^{3}$ Chemistry and ${ }^{4}$ Biochemistry, Tokyo Medical University, Tokyo 160-8402, Japan

Received December 1, 2009; Accepted February 10, 2010

DOI: $10.3892 /$ or_00000790

\begin{abstract}
The present study investigated the anticancer activity of 2-aminophenoxazine-3-one (Phx-3) and 2-amino-

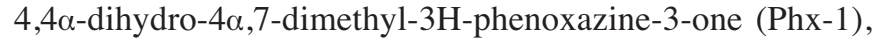
which were obtained by improved preparation methods using bovine erythrocyte suspension, on colon cancer cell lines COLO201, DLD1 and PMCO1 in vitro. The preparation methods for Phx-1 and Phx-3 had the advantages of extensively shortening reaction time and reducing sample volumes up to one-seventh during treatment, compared with the conventional method using bovine hemoglobin solution, resulting in extensive reduction of handling time. $\mathrm{Phx}-1$ and Phx-3 thus obtained were identified as pure by the absorption spectra and NMR spectra. These phenoxazines exerted strong, dose-dependent anticancer activity against colon cancer cell lines COLO201, DLD1 and PMCO1 in vitro and induced apoptosis of these cells. The present results demonstrate that $\mathrm{Phx}-1$ and $\mathrm{Phx}-3$, which were prepared by extensively improved methods using bovine erythrocytes, may be useful as therapeutic drugs against colon cancer that is intractable to chemotherapy.
\end{abstract}

\section{Introduction}

Colorectal cancer is one of a major public health problems worldwide, and its incidence is increasing annually (1-3). Regardless of extensive research, the overall five-year survival rate in colorectal cancer patients remains low. In order to overcome such an alarming situation, drugs to prevent colorectal cancer are urgently required. Although few chemotherapeutic agents act effectively against colo-

Correspondence to: Dr Akio Tomoda, Department of Biochemistry, Tokyo Medical University, 6-1-1 Shinjuku, Tokyo 160-8402, Japan

E-mail: tomoda@tokyo-med.ac.jp

Key words: phenoxazines, anticancer activity, colon cancer cells rectal cancer, it has been demonstrated that 2-amino- $4,4 \alpha-$ dihydro-4 $\alpha, 7$-dimethyl-3H-phenoxazine-3-one (Phx-1) and 2-aminophenoxazine-3-one (Phx-3), the oxidative form of phenoxazines, exert strong anticancer activity against a variety of cancer cells in vitro and in vivo (4-9). However, it is still unclear whether or not these phenoxazines are effective against colon cancers that are intractable to chemotherapeutic agents $(2,3)$.

Phenoxazines are a tricyclic chromophore in which the nitrogen atom and oxygen atom are present, and can be synthesized chemically. The chemically synthesized phenoxazines are usually the reduced form and seem to exert little biological activity, probably due to lower solubility in water. Actinomycin D produced by Saccharomyces actinomyces is a typical phenoxazine compound that exerts strong anticancer activity but with extensive adverse effects (10) and conforms to the oxidative form. Phx-1 and $\mathrm{Phx}-3$, which are produced biologically by the reactions of 2-amino-5-methylphenol and $o$-aminophenol with human or bovine hemoglobin solution $(11,12)$, conform to the oxidative form. In particular, Phx-3 intercalates DNA in a cell-free system, similarly to Actinomycin D (13). Phx-1 and Phx-3 are relatively water-soluble, and elicit various biological activities, including anticancer effects (4-9). Therefore, rapid bulk preparation of Phx-1 and $\mathrm{Phx}-3$ is needed for further investigation of their biological activity and their application to medical use. The conventional procedures for obtaining more than $1 \mathrm{~g}$ Phx-1 and Phx-3 require one month because of the preparation of a large quantity of bovine hemoglobin solution, six days of incubation for the reactions of 2-amino-5-methylphenol or $o$ aminophenol with bovine hemoglobin solution at $37^{\circ} \mathrm{C}$, and a large volume of methanol for extracting the final products. Moreover, it is time-consuming to evaporate methanol from a large quantity of crude solutions, including Phx-1 and Phx-3.

Thus, we decided to eliminate these effort-wasting and time-consuming procedures for the bulk preparation of $\mathrm{Phx}-1$ and Phx-3. The present report describes an extensively improved method for preparing Phx-1 and Phx-3 using bovine erythrocyte suspension. This method enabled us to obtain a large quantity of $\mathrm{Phx}-1$ and $\mathrm{Phx}-3$ in a relatively short period. Since Phx-1 and Phx-3 thus prepared were found to be pure as determined by examining absorption spectra, Nuclear 
Magnetic Resonance (NMR) spectra, and thin layer chromatography, we investigated whether these compounds may exert anticancer activity against colon cancer cell lines, COLO201, DLD1 and PMCO1 in vitro.

\section{Materials and methods}

Reagents. o-Aminophenol was purchased from Wako (Osaka, Japan), and 2-amino-5-methylphenol was purchased from Tokyo Kasei (Tokyo). Sephadex LH20 was obtained from GE Healthcare Biosciences AB (Uppsala, Sweden). Plates for thin-layer chromatography were purchased from Merck KGaA (Darmstadt, Germany). Ethanol and methanol (special grade) were purchased from Wako.

Cell lines. Three human colon carcinoma cell lines, COLO201, DLD1 and PMCO1, were kindly provided by Dr Akihiko Tsuchida (Third Department of Surgery, Tokyo Medical University). The cells were maintained in continuous culture in RPMI-1640 medium (Gibco, Grand Island, NY, USA) supplemented with $10 \%$ fetal calf serum (FCS, Hyclone Co., Ltd., Logan, UT, USA), 2 mM L-glutamine, penicillin $(50 \mathrm{U} / \mathrm{ml})$, and streptomycin $(100 \mu \mathrm{g} / \mathrm{ml})$ in a humidified incubator containing $5 \% \mathrm{CO}_{2}$ and $95 \%$ air at $37^{\circ} \mathrm{C}$.

Assessment of viable cell count and morphological assessment of culture cells. COLO201, DLD1 and PMCO1 cells were seeded in a 96-well flat bottom microplate (Nunc, Roskilde, Denmark) at $2.5 \times 10^{4}$ cells/well, treated with various concentrations of $\mathrm{Phx}-1$ or $\mathrm{Phx}-3$ prepared by procedures using bovine erythrocyte suspension, and then incubated for $72 \mathrm{~h}$, as described above. The samples were subjected to analysis of cell viability and morphology at the indicated time.

The number of viable cells was assessed using a cell viability assay kit, Cell Titer Blue (Promega Co. Ltd., Madison, WI), with fluorescence measurements at $570 \mathrm{~nm}$ for excitation and $590 \mathrm{~nm}$ for fluorescence emission.

For morphological assessment, the cell suspension was taken out at the indicated time and was sedimented in a Shandon Cytospin II (Shandon, Pittsburgh, PA). The preparations were then stained with May-Grünwald-Giemsa solution. Morphological changes were assessed by digital microscopy using BZ-8000 (Keyence Co., Osaka, Japan)

Procedures for rapid bulk preparation of Phx-1 and Phx-3 in bovine erythrocyte suspension. The procedures for rapid bulk preparation of Phx-1 and Phx-3 using bovine erythrocyte suspension are summarized in Fig. 1. The present method adopted bovine erythrocytes for reaction with 2-amino-5methylphenol or $o$-aminophenol, instead of bovine hemoglobin solution as described in (11) and (12). First, 10 liters (lt) of bovine blood was centrifuged at $10000 \mathrm{~g} \mathrm{x} 1 \mathrm{~min}$. After removal of supernatant and buffy coats, the erythrocytes were washed twice with $0.9 \% \mathrm{NaCl}$ solution. Four liters of packed erythrocytes was suspended in 12 lt of $0.9 \%$ $\mathrm{NaCl}$ solution. This erythrocyte suspension was divided into two parts (8 lt each).

Next, 4 g 2-amino-5-methylphenol or $o$-aminophenol was added to $200 \mathrm{ml} 0.9 \% \mathrm{NaCl}$ solution and then treated with $400 \mathrm{ml}$ of $0.2 \mathrm{~N} \mathrm{HCl}$ solution with $0.9 \% \mathrm{NaCl}$, in order to

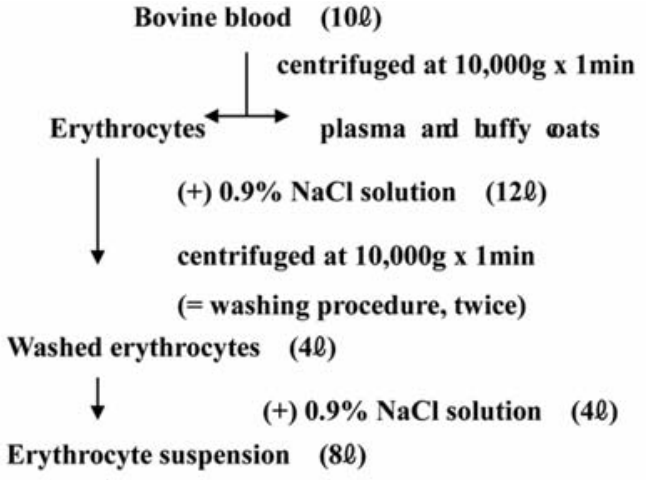

(+) $5 \mathrm{mM} o$-aminophenol in

$0.9 \% \mathrm{NaCl}$ solution

or 5mM 2-amino-5-methylphenol

in $0.9 \% \mathrm{NaCl}$ solution

Reaction mixtures

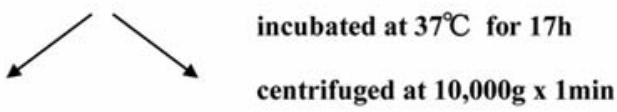

Erythrocyte

Supernatant

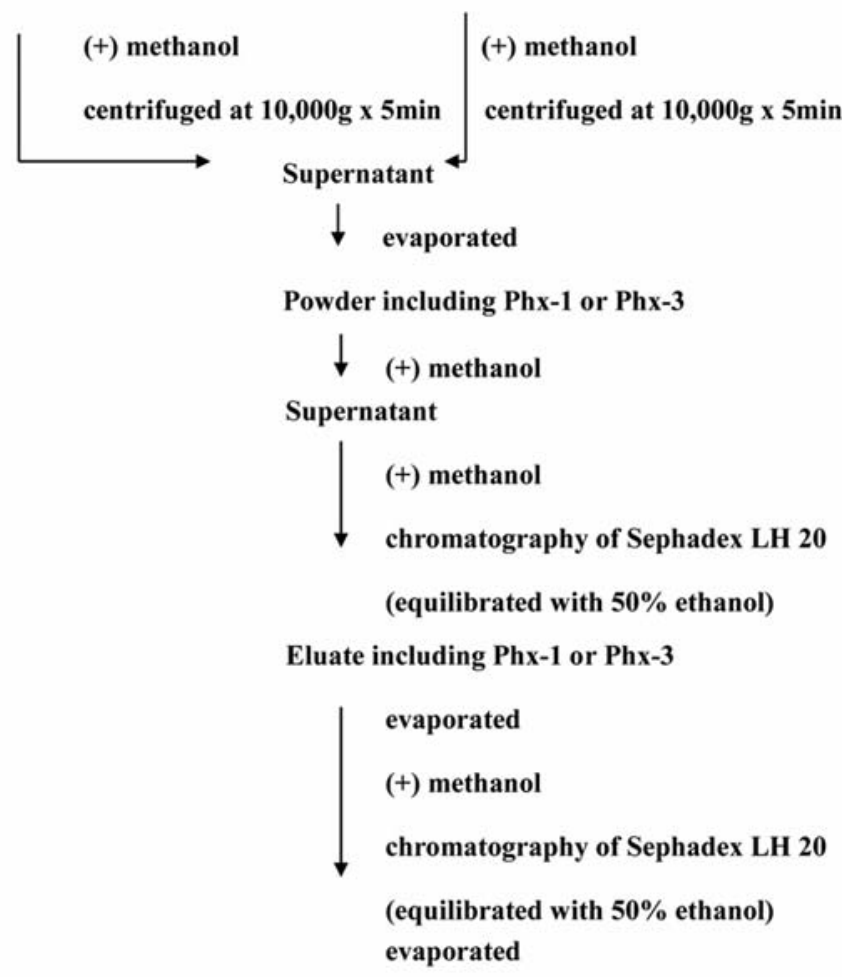

Powder of pure Phx-1 or Phx-3

Figure 1. Procedures for preparation of $\mathrm{Phx}-1$ or $\mathrm{Phx}-3$ by bovine erythrocytes.

dissolve these compounds in water completely. Four hundred milliliters of $0.2 \mathrm{~N} \mathrm{NaOH}$ solution with $0.9 \% \mathrm{NaCl}$ was added to the solution of 2-amino-5-methylphenol or $o$-aminophenol to neutralize the solution and make final concentrations of $5 \mathrm{mM}$. Next, $1 \mathrm{lt}$ of these solutions was quickly added to the erythrocyte suspension $(8 \mathrm{lt})$. Since the suspension $\mathrm{pH}$ is rapidly alkalized after the addition of 2-amino-5-methylphenol or $o$-aminophenol solution due to the oxidation of 
erythrocytic hemoglobin by these compounds, it was neutralized to $\mathrm{pH} 7.2$ by adding $0.2 \mathrm{~N} \mathrm{HCl}$ solution with $0.9 \%$ $\mathrm{NaCl}$. The erythrocyte suspension with 2-amino-5-methylphenol or $o$-aminophenol was the set at $37^{\circ} \mathrm{C}$ in a temperature-controlled incubator and incubated for $17 \mathrm{~h}$.

The cell suspension was centrifuged at $10000 \mathrm{~g} \mathrm{x} 1 \mathrm{~min}$, and a supernatant containing brown (for Phx-1) or red-brown (for Phx-3) compounds was obtained. This treatment caused little hemolysis of the erythrocyte. The packed erythrocytes were treated with the same volume of methanol to denature the cells. After centrifugation of the denatured cells at $10000 \mathrm{~g}$ x $1 \mathrm{~min}$, the brown or red-brown supernatant was obtained and mixed with the supernatant previously obtained. The supernatant was set at room temperature for $1 \mathrm{~h}$, and the denatured proteins were removed by centrifuging the supernatant at $10000 \mathrm{~g}$ x $5 \mathrm{~min}$.

Transparent brown (for Phx-1) or red-brown (for Phx-3) supernatant was subjected to evaporation using an evaporator (Eyela, Tokyo). It takes $2 \mathrm{~h}$ to evaporate solvents from $3 \mathrm{lt}$ of supernatant. The remaining powder was dissolved in methanol. Since water-soluble salts such as $\mathrm{NaCl}$ and organic compounds in the erythrocytes are not soluble in methanol, the brown or red-brown supernatant could be obtained by decantation. The same treatment was repeated twice until no salt sediment was observed. Finally, the brown or red-brown powder was dissolved in $500 \mathrm{ml}$ methanol.

This crude solution of Phx-1 or Phx-3 was subjected to a column $(10 \times 40 \mathrm{~cm})$ packed with Sephadex LH20 in 50\% ethanol. The elution of the crude Phx-1 or Phx-3 was then initiated by adding $50 \%$ ethanol, and column chromatography was performed for $12 \mathrm{~h}$. For the chromatography of crude Phx-1, brownish green eluates were obtained as the faster phase and discarded. The second brown eluate including Phx-1 was collected and evaporated to make a powder, which was dissolved in $100 \mathrm{ml}$ methanol. The solution was then added to a column $(4 \times 30 \mathrm{~cm})$ packed with Sephadex LH20 with $50 \%$ ethanol solution and was eluted with $50 \%$ ethanol solution. The brown eluates were obtained and evaporated to powder. This powder was subjected to measurement of absorption spectra, and ${ }^{1} \mathrm{H}$ NMR and ${ }^{13} \mathrm{C}$ NMR spectra detected by a JEOL-JNM-ECP300 spectrometer, and to thinlayer chromatography.

For the chromatography of crude Phx-3, brown eluates, which came down faster, were discarded. The second redbrown eluate including Phx-3 was collected. The eluate was then evaporated to make a powder, which was dissolved in $100 \mathrm{ml}$ methanol. This solution was applied to a column $(4 \mathrm{x}$ $30 \mathrm{~cm}$ ) packed with Sephadex LH20 with $50 \%$ ethanol solution and was eluted with $50 \%$ ethanol solution. Red-brown eluates were obtained and evaporated to powder. This powder was used to identify Phx-3 by absorption spectra, ${ }^{1} \mathrm{H}$ NMR and ${ }^{13} \mathrm{C}$ NMR spectra, and thin-layer chromatography. These procedures yielded Phx-1 and Phx-3 in $8.5 \%$ and $9 \%$ yield.

\section{Results}

Identification of $\mathrm{Phx}-1$ and $\mathrm{Phx}-3$ obtained by reactions with bovine erythrocyte suspension. We obtained powders of pure Phx-1 and Phx-3 according to the method using bovine erythrocyte suspension, as described in Fig. 1. The color of

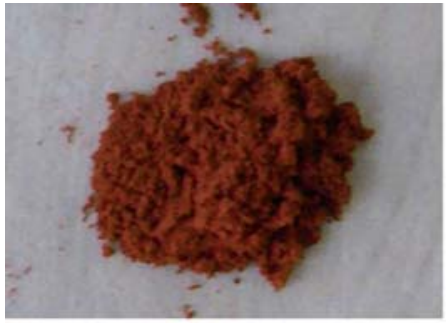

Phx-1
Phx-3

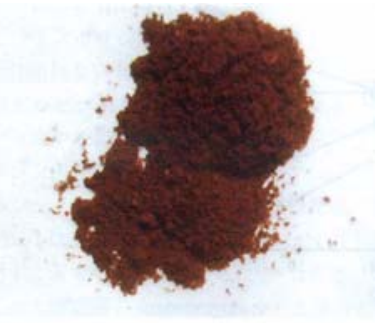

Figure 2. Photos of Phx-1 and Phx-3 powder.

(A)<smiles>Cc1ccc2c(c1)OC1(C)CC(=O)C(N)=CC1=N2</smiles>

(B)

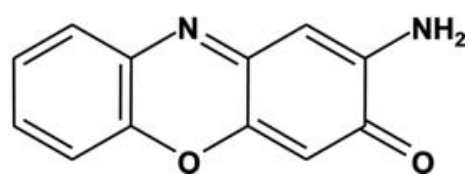

Figure 3. Chemical structure of Phx-1 and Phx-3. (A) Phx-1; (B) Phx-3.

Table I. NMR data for Phx-1.

${ }^{1} \mathrm{H}-\mathrm{NMR}\left(300 \mathrm{MHz}, \mathrm{DMSO}-\mathrm{d}_{6}\right): \delta: 1.10(\mathrm{~s}, 3 \mathrm{H}), 2.27$ (s, $3 \mathrm{H}), 2.98(\mathrm{~d}, 1 \mathrm{H}), 3.18(\mathrm{~d}, 1 \mathrm{H}) 6.05(\mathrm{~s}, 1 \mathrm{H}), 6.36$ (brs, 2H), $6.71(\mathrm{~s}, 1 \mathrm{H}), 6.79$ (brd, 1H), $7.09(\mathrm{~d}, 1 \mathrm{H})$

${ }^{13} \mathrm{C}-\mathrm{NMR}\left(76 \mathrm{MHz}, \mathrm{DMSO}-\mathrm{d}_{6}\right): \delta: 160.70,143.77,132.63$, $122.96,105.86,49.18,20.88$

APCI-MS: $243\left(\mathrm{MH}^{+}\right)$

purified $\mathrm{Phx}-1$ and $\mathrm{Phx}-3$ were yellowish orange and red brown, respectively (Fig. 2).

The chemical structure of $\mathrm{Phx}-1$ and $\mathrm{Phx}-3$ prepared by conventional methods using bovine hemoglobin solution has been determined by examining NMR spectra of these compounds, and is presented in Fig. 3. Thus, we examined the ${ }^{1} \mathrm{HNMR}$ and ${ }^{13} \mathrm{CNMR}$ spectra of $\mathrm{Phx}-1$ and $\mathrm{Phx}-3$ prepared by reactions with bovine erythrocyte suspension. The measured NMR data for these Phx-1 and Phx-3 are demonstrated in Tables I and II, respectively. From these results it was indicated that the NMR signals of Phx-1 and Phx-3 obtained by the present method showed identical NMR signals to those of these phenoxazines prepared by the conventional method using bovine hemoglobin solution $(11,12)$. Though the data for absorption spectra and thin-layer chromatography for Phx-1 and Phx-3 obtained by the present procedures are not illustrated, the results indicated that the absorption spectra between 220 and $600 \mathrm{~nm}$ and the moving position of these 
Table II. NMR data for Phx-3.

${ }^{1} \mathrm{HNMR}\left(300 \mathrm{MHz}, \mathrm{DMSO}-\mathrm{d}_{6}\right): \delta: 6.37(\mathrm{~s}, 1 \mathrm{H}), 6.38(\mathrm{~s}, 1 \mathrm{H})$, $6.82(\mathrm{bs}, 2 \mathrm{H}), 7.37-7.53(\mathrm{~m}, 3 \mathrm{H}), 7.71(\mathrm{dd}, 1 \mathrm{H})$

${ }^{13} \mathrm{CNMR}\left(76 \mathrm{MHz}, \mathrm{DMSO}-\mathrm{d}_{6}\right.$ ): $\delta: 180.3,149.0,148.3,147.4$, $142.0,133.8,128.9,128.0,125.4,116.0,103.5,98.4$

\section{APCI-MS: $213\left(\mathrm{MH}^{+}\right)$}

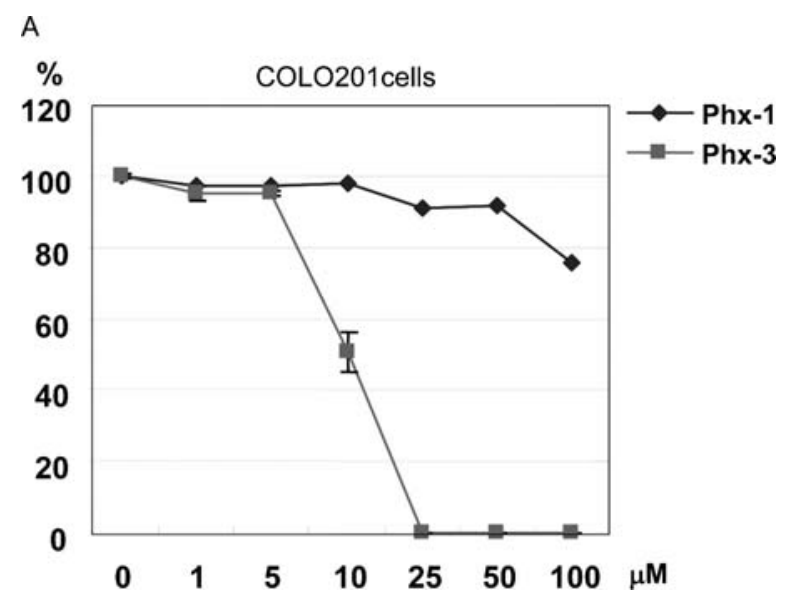

B

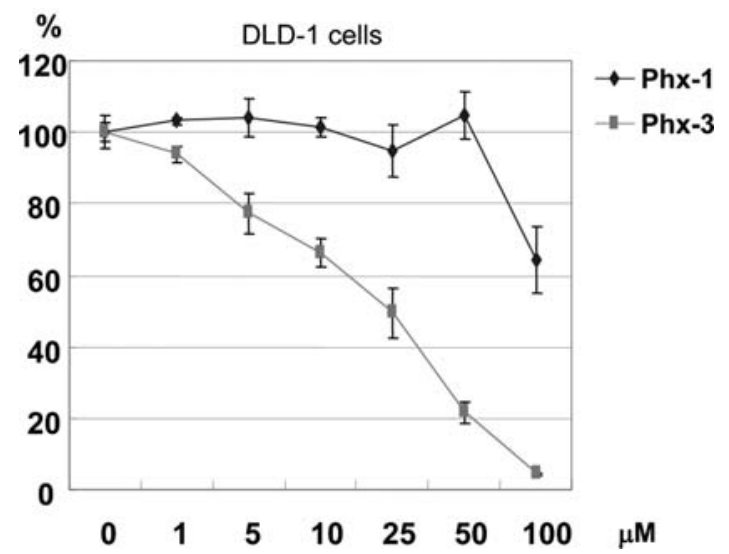

$\mathrm{C}$

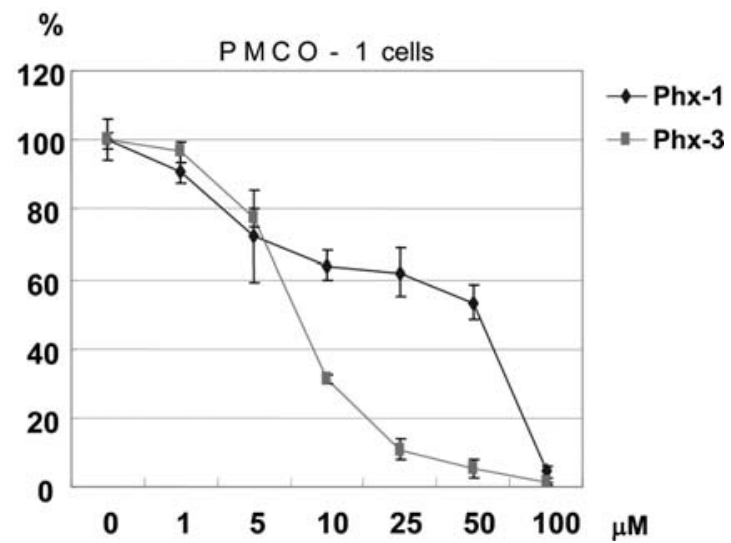

Figure 4. Effects of different concentrations of Phx-1 and Phx-3 prepared by the present method using bovine erythrocyte suspension on the viability of human colon carcinoma cell lines COLO201, DLD1 and PMCO1. (A) COLO201 cells; (B) DLD1 cells; (C) PMCO1 cells. phenoxazines on a thin-layer chromatography were completely identical to those prepared by the conventional method using bovine hemoglobin solutions, as well $(11,12)$.

Cell growth inhibition in colon carcinoma cell lines after 72- $h$ exposure to Phx-1 and Phx-3 in vitro. We examined the anticancer activity of Phx-1 and Phx-3 obtained by the present procedures against colon cancer cell lines COLO201, DLD1 and PMCO1. Fig. 4 indicates the effects of different concentrations of $\mathrm{Phx}-1$ or $\mathrm{Phx}-3$ on the viability of these colon cancer cell lines for $72 \mathrm{~h}$. Phx-1 and $\mathrm{Phx}-3$ suppressed the viability of COLO201 (Fig. 4A), DLD1 (Fig. 4B) and PMCO1 (Fig. 4C) in a dose-dependent manner. In particular, Phx-3 demonstrated stronger anticancer activity against these cell lines. The $\mathrm{IC}_{50}$ (50\% inhibition of cell growth) of $\mathrm{Phx}-3$ was $9 \mu \mathrm{M}$ for COLO201 cells, $12 \mu \mathrm{M}$ for DLD1 cells and $6 \mu \mathrm{M}$ for PMCO1 cells. However, anticancer effect of Phx-1 was much less than that of Phx-3. The $\mathrm{IC}_{50}$ of $\mathrm{Phx}-1$ was $25 \mu \mathrm{M}$ for PMCO1. The viability of COLO201 cells and DLD1 cells was suppressed by 20 and $35 \%$ at the concentrations of $100 \mu \mathrm{M}$ Phx-1.

We examined morphological changes in COLO201, DLD1 and PMCO1 cells treated with $100 \mu \mathrm{M} \mathrm{Phx}-1$ or $10 \mu \mathrm{M}$ Phx-3 for $72 \mathrm{~h}$, which could be demonstrated by MayGrünwald-Giemsa staining (Fig. 5). As a result, the DLD-1 cells (the middle columns of Fig. 5) exhibited the typical morphological features of apoptosis accompanied by condensation of the nuclear chromatin structure and nuclear fragments when treated with Phx-3. Both COLO201 (the upper columns of Fig. 5) and PMCO1 cells (the bottom columns of Fig. 5) indicated shrunken nuclei and destruction of cellular membrane structure in response to Phx-3. However, in some (but not all) cells, apoptotic features were observed in all three cell lines, in response to $\mathrm{Phx}-1$. These results suggest that Phx-3 may exert stronger apoptogenic activity against colon cancer cell lines COLO201, DLD1 and PMCO1.

\section{Discussion}

Colorectal cancer is one of the leading cause of cancer mortality, and afflicts the elderly. Its incidence is very high among cancers in Western countries and in Japan. Surgical therapy is a first-line treatment of this cancer, and adjuvant chemotherapy is often applied to the patients with advanced colorectal cancer. 5-FU is commonly selected for the treatment of colon cancer $(2,3)$. However, in addition to drug resistance against 5-FU, its adverse effects are troublesome for the treatment. Phenoxazine compounds are considered to exert less anticancer effects against various cancer cells and less toxic against humans (14), though Actinomycin D, a kind of phenoxazine, is exclusively effective to Wilms's tumor (15). Therefore, phenoxazine compounds have not been taken into accounts for the treatment of the patients with cancer.

From the view-points of chemical structure, Actinomycin D conforms to the oxidative form of phenoxazine, though many chemically-produced phenoxazines conform to the reduced one. In light of the fact that Phx-1 and Phx-3 conform to the oxidative form of phenoxazine, it is probable that $\mathrm{Phx}-1$ and Phx-3 may exert anticancer effects on cancer cells, similarly to Actinomycin D. It has been indicated that Phx-1 and Phx-3 

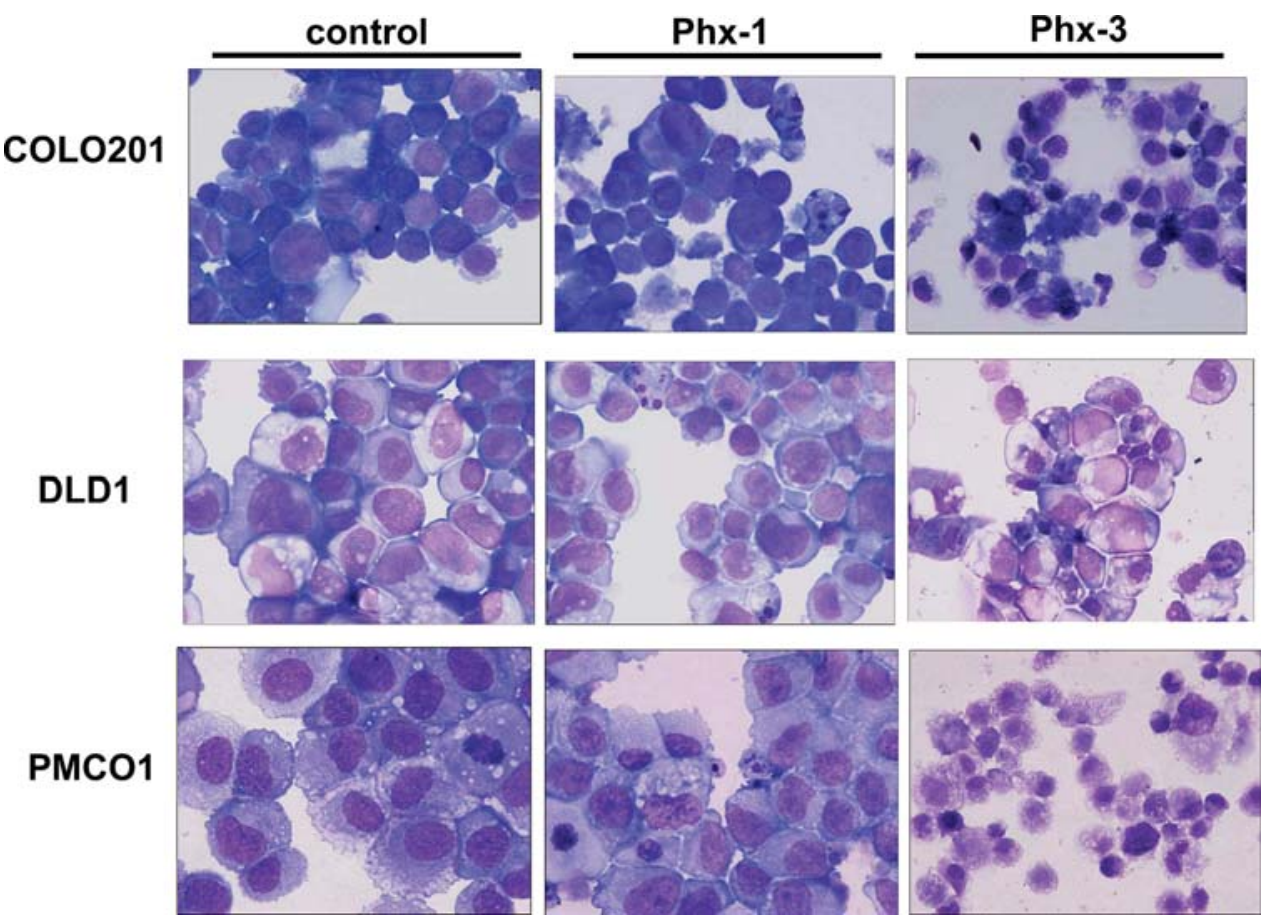

Figure 5. Morphological examination of the effects of Phx-1 and Phx-3 prepared by the present method on human colon cancer cell lines COLO201, DLD1 and PMCO1. COLO201, DLD1 and PMCO1 cells were treated with $100 \mu \mathrm{M} \mathrm{Phx}-1$ or $10 \mu \mathrm{M}$ Phx-3 for $72 \mathrm{~h}$. Upper column, COLO201 cells; middle column, DLD1 cells; bottom column, PMCO1 cells.

exert anticancer effects against various species of cancer cells, and that the anticancer activity of $\mathrm{Phx}-3$ is much stronger than that of Phx-1 (4-9). In the present study, we developed an extensively improved method to prepare Phx-1 and Phx-3 by means of bovine erythrocyte suspension (Fig. 1). It is therefore of interest to evaluate the anticancer activity of Phx-1 and Phx-3 prepared by the present method.

The oxidative form of phenoxazines is produced by reacting $o$-aminophenol and its derivatives with bovine hemoglobin (11), human hemoglobin (16), cytochrome oxidase (17), phenoxazinone synthase (18) and Actinomycin synthase (19). Tomoda et al (20) also reported that $\mathrm{Phx}-3$, is produced in human erythrocytes, being in agreement with the report of Eckert and Eyer (21) that Phx-3 is produced in dog blood. Furthermore, Kohno et al (22) recently reported that APO (equivalent to $\mathrm{Phx}-3 /$ questiomycin $\mathrm{A}$ ) is present in edible brown mushrooms. Thus, it is conceivable that the oxidative form of phenoxazines may be specifically produced by biological systems.

Based on these findings, a method for bulk preparation of Phx-1 and Phx-3 has been devised by reacting 2-amino-5methylphenol and $o$-aminophenol with bovine hemoglobin solution $(1,12)$. However, the purification process of these phenoxazines was time-consuming and required much effort; therefore, improved methods are necessary. In the present study, we found that $\mathrm{Phx}-1$ and $\mathrm{Phx}-3$ were produced by bovine erythrocytes in a large quantity when 2-amino-5methylphenol or $o$-aminophenol was added to the cell suspension, and reactions were undertaken at $37^{\circ} \mathrm{C}$ for $17 \mathrm{~h}$ (Fig. 1). The phenoxazine compounds produced by these procedures were identical with $\mathrm{Phx}-1$ and $\mathrm{Phx}-3$ (Tables I and II) that were obtained by the conventional methods using bovine hemoglobin $(11,12)$. The reaction time was much shorter in bovine erythrocyte suspension $(17 \mathrm{~h})$ than in bovine hemoglobin solution (six days), and a negligible amount of hemolysis was detected during the reaction (Fig. 1). The present procedures were far more advantageous than the conventional procedures with bovine hemoglobin (11), in terms of shortening the handling time, reducing efforts during treatment of reaction mixtures, and reducing the volume of methanol for extracting and purifying $\mathrm{Phx}-1$ and $\mathrm{Phx}-3$.

Phx-1 and Phx-3 prepared by the conventional method using bovine hemoglobin solution (11) have been demonstrated to exert anticancer effects against a variety of cancer cells, including malignant melanoma cells (6), gastric cancer cells (7), neuroblastoma cells (8), multiple myeloma cells (9) and pancreatic cancer cells (23), though the anticancer activity of $\mathrm{Phx}-3$ was much stronger than that of $\mathrm{Phx}-1$ in these cancer cells. Thus, we studied the anticancer effects of Phx-1 and Phx-3 prepared by the present methods using bovine erythrocyte suspension on colon cancer cell lines COLO201, DLD1 and PMCO1 in vitro. Phx-3 prepared by the present method exerted anticancer activity against these cancer cell lines, while Phx-1 exerted less anticancer effect (Fig. 4). We found that Phx-3 exerts anticancer effect against three colon cancer cell lines, COLO201, DLD1 and PMCO1 at lower concentrations $\left(\mathrm{IC}_{50}: 6 \mu \mathrm{M}\right.$ for PMCO1 cells, $12 \mu \mathrm{M}$ for DLD1 cells and $9 \mu \mathrm{M}$ for COLO201 cells), indicating that Phx-3 has strong anticancer activity in vitro, which will be empirically expected to exert stronger anticancer activity in vivo.

We also found that Phx-3 caused apoptosis of COLO201, DLD1 and PMCO1 cells (Fig. 5), though the apoptotic manner seemed to differ among cell species, and mechanism 
for the apoptogenic activity of Phx-3 against these colon cancer cells is under investigation. Since it has been recognized that the drugs inducing apoptosis cause less adverse effects, present results suggest that Phx-3 may exert less adverse effects, being consistent with the report that less adverse effect of Phx-3 was exhibited in mice (6). According to Kohno et al (22), Phx-3/APO did not cause weight loss or gastrointestinal injury, when 500-1500 mg/kg Phx-3/APO was orally administered to mice, suggesting that this compound would exert less adverse effect. Therefore, Phx-3 may be useful for chemotherapy and adjuvant chemotherapy of colon cancer that is intractable to chemotherapy.

\section{Acknowledgements}

The present research was supported in part by funds from the Private University Strategic Research-Based Support Project (Molecular Information-based Intractable Disease Research Project) (2008 2013).

\section{References}

1. Saltz LB, Cox JV, Blanke C, Rosen LS, Fehrenbacher L, Moore MJ, Maroun JA, Ackland SP, Locker PK, Pirotta N, Elfring GL and Miller LL: Irinotecan plus fluorouracil and leucovorin for metastatic colorectal cancer. Irinotecan Study Group. N Engl J Med 343: 905-914, 2000.

2. Hoff PM, Ansari R, Batist G, Cox J, Kocha W, Kuperminc M, Maroun J, Walde D, Weaver C, Harrison E, Burger HU, Osterwalder B, Wong AO and Wong R: Comparison of oral capecitabine vs intravenous fluorouracil plus leucovorin as firstline treatment in 605 patients with metastatic colorectal cancer: results of a randomized phase III study. J Clin Oncol 19: 2282-2292, 2001.

3. Dulabh K, Monga MD and O'Connell MJ: Surgical adjuvant therapy for colorectal cancer: current approaches and future directions. Anal Surg Oncol 13: 1021-1034, 2006

4. Mori $\mathrm{H}$, Honda $\mathrm{K}$, Ishida $\mathrm{R}$ and Tomoda $\mathrm{A}$ : Antitumor activity of 2-amino-4,4 $\alpha$-dihydro-4 $\alpha, 7$-dimethyl-3H-phenoxazine-3-one against Meth A tumor transplanted into BALB/c mice. AntiCancer Drugs 11: 653-765, 2000.

5. Shimamoto T, Tomoda A, Ishida R and Ohyashiki K: Antitumor effects of a novel phenoxazine derivative on human leukemia cell lines in vitro and in vivo. Clin Cancer Res 7: 704-708, 2001.

6. Miyano-Kurosaki N, Kurosaki K, Hayashi M, Takaku H, Hayafune M, Shrato K, Kasuga T, Endo T and Tomoda A: 2Aminophenoxazine-3-one suppresses the growth of mouse malignant melanoma B16 cells transplanted into C57BL/6Cr Slc mice. Biol Pharm Bull 29: 2197-2201, 2006.

7. Kasuga T, Tabuchi T, Shirato K, Imaizumu K and Tomoda A: Caspase-independent cell death revealed in human gastric cancer cell lines, MKN45 and KATO III treated with phenoxazine derivatives. Oncol Rep 17: 409-415, 2007.
8. Shirato K, Imaizumi K, Abe A and Tomoda A: Phenoxazine derivatives, 2-amino-4,4 $\alpha$-dihydro- $4 \alpha, 7$-dimethyl-3Hphenoxazine-3-one and 2-aminophenoxazine-3-one-induced apoptosis through a caspase-independent mechanism in human neuroblastoma cell line NB-1 cells. Biol Pharm Bull 30: 331-336, 2007.

9. Shirato K, Imaizumi K, Miyazawa K, Takasaki A, Mizuguchi J, Che X-F, Akiyama S and Tomoda A: Apoptosis induction preceded by mitochondrial depolarization in multiple myeloma cell line U266 by 2-aminophenoxazine-3-one. Biol Pharm Bull 31: 62-67, 2008.

10. Hollstein U: Actinomycin: chemistry and mechanism of action. Chem Rev 74: 625-652, 1974.

11. Tomoda A, Arai S, Ishida R, Shimamoto T and Ohyashiki K: An improved method for the rapid preparation of 2-amino- $4,4 \alpha-$ dihydro-4 $\alpha, 7$-dimethyl-3H-phenoxazine-3-one, a novel antitumor agent. Bioorg Med Chem Lett 11: 1057-1058, 2001.

12. Shimizu S, Suzuki M, Miyazawa K, Yokoyama T, Ohyashki K, Kiyazaki K and Tomoda A: Phenoxazine compounds produced by the reactions with bovine hemoglobin show antimicrobial activity against non-tuberculosis mycobacteria. Tohoku J Exp Med 203: 47-52, 2004.

13. Chibber BAK, Balasubramanian A and Viswanatha T: Binding of actinomycin chromophore analogues to DNA. Can J Biochem 51: 204-217, 1972.

14. Hoerlein U, Risse KH and Wirth W: Pharmacological comparison of phenoxazine and phenothiazine compounds. Med Chem: Abhandl Med Chem Forschungsstaetten Farbenfabriken Bayer 7: 79-98, 1963.

15. Ward HW: Actinomycin D for Wilms's tumor. Br Med J 1: 42, 1973.

16. Tomoda A, Hamashima H, Arisawa M, Kikuchi T, Tezuka Y and Koshimura S: Phenoxazinone synthesis by human hemoglobin. Biochim Biophys Acta 1117: 3036-3140, 1992.

17. Nagasawa HT, Gutmann HR and Morgan MA: The oxidation of $o$-aminophenols by cytochrome c and cytochrome oxidase. II. Synthesis and identification of oxidation products. J Biol Chem 234: 1600-1604, 1959.

18. Barry CE, Nayer PG and Begley TP: Phenoxazinone synthase: enzymatic catalysis of an amonophenol oxidative cascade. J Am Chem Soc 110: 3333-3334, 1988.

19. Katz E and Weissbach H: Biosynthesis of the actinomycin chromophore; Enzymatic conversion of 4-methyl-3-hydroxyanthranilic acid to actinocin. J Biol Chem 237: 882-886, 1962.

20. Tomoda A, Yamaguchi J, Kojima H, Amemiya H and Yoneyama Y: Mechanism of $o$-aminophenol metabolism in human erythrocytes. FEBS Lett 196: 44-48, 1986.

21. Eckert KG and Eyer P: Differences in the reactions of isomeric ortho- and para-aminophenols with hemoglobin. Biochem Pharmacol 32: 1019-1027, 1983.

22. Kohno K, Miyake M, Sano O, Tanaka-Kataoka M, Yamamoto S, Koya-Miyata S, Arai N, Mitsukiyo F, Watanabe H, Ushio S, Iwaki $\mathrm{K}$ and Fukuda S: Anti-inflammatory and immunomodulatory properties of 2-amino-3H-phenoxazin-3-one. Biol Pharm Bull 31: 938-1945, 2008.

23. Kato S, Shirato K, Imaizumi K, Toyota H, Mizuguchi J, Odawara M, Che X-F, Akiyama S, Abe A and Tomoda A: Anticancer effects of phenoxazine derivatives combined with tumor necrosis factor-related apoptosis-inducing ligand on pancreatic cancer cell lines, KLM-1 and MIA-PaCa-2. Oncol Rep 15: 843-848, 2006. 